\title{
A Competitividade do Regadio de Alqueva em Portugal: o caso do bloco de rega do Monte Novo ${ }^{1}$
}

\begin{abstract}
Maria José Palma Lampreia dos Santos², Rui Manuel de Sousa Fragoso ${ }^{3}$, Pedro Damião de Sousa Henriques ${ }^{4}$ e Maria Leonor da Silva Carvalho $^{5}$
\end{abstract}

Resumo: O objectivo deste estudo é avaliar a competitividade do regadio de Alqueva no Sul de Portugal na região Alentejo. O estudo foi realizado com base em três grupos de explorações agrícolas representativas seleccionadas de uma amostra de explorações agrícolas do bloco de rega do Monte Novo. Para cada uma delas, foi desenvolvido um modelo de programação matemática multi-período adaptado às suas características específicas. Os principais resultados permitem concluir que a Política Agrícola Comum e a Directiva Quadro da Água condicionam a competitividade do regadio nesta região. No entanto, a adopção de novas tecnologias de produção permitirá contrariar esses efeitos negativos e assegurar a competitividade futura do regadio.

Palavras-chaves: regadio, programação multi-período, investimento, política agrícola comum.

Abstract: The main purpose of this paper is evaluating the competitiveness of the Alqueva irrigation project in the Alentejo region, South of Portugal. This study was based on three representative farms which were selected from one farm sample of the Monte Novo irrigation scheme. For each farm, it was developed a multi-period mathematical programming model which represents its specific skills. Results show that Common Agricultural Policy and Water Framework Directive have adverse impact on competitiveness. However, the

1 Trata-se de um artigo cujos autores são de Portugal. Dessa forma, o artigo está escrito em português utilizado em Portugal, em que não há correspondência de termos com o português utilizado no Brasil, mesmo para textos científicos em economia.

2 Professora Auxiliar, Faculdade de Economia e Gestão, Universidade Lusófona do Porto, Cernas. E-mail: mjpls1963@gmail.com

3 Professor Auxiliar com Agregação, Departamento de Gestão, Escola de Ciências Sociais, Universidade de Évora, Cefage. E-mail: rfragoso@uevora.pt

4 Professor Associado, Departamento de Economia, Escola de Ciências Sociais, Universidade de Évora, Cefage. E-mail: pdamiao@uevora.pt

5 Professora Associada, Departamento de Economia, Escola de Ciências Sociais, Universidade de Évora, Icaam. E-mail: leonor@uevora.pt 
adoption of new technological innovations and more environmental sustainable systems of agricultural production might help to mitigate those adverse impacts and promote the competitiveness of this irrigation project.

Key-words: irrigation, multi-period programming, investment, common agricultural policy.

Classificação JEL: Q12, Q18, Q15.

\section{Introdução}

O Empreendimento de Fins Múltiplos de Alqueva (EFMA) é um grande investimento público que está a ser realizado na região Alentejo, no Sul de Portugal, que prevê o abastecimento de água às populações, a produção de energia hidroeléctrica e a criação de 110 mil hectares novos de regadio. Este potencial, associado às condições edafoclimáticas da região e à sua estrutura fundiária concentrada em grandes explorações, constitui uma oportunidade única quer para a adopção de um leque mais diversificado de culturas e com maior valor acrescentado, quer para a actividade agrícola empresarial. Os principais desafios no planeamento e implementação da valia agrícola deste empreendimento relacionam-se com a reconversão das actuais áreas de culturas de sequeiro em culturas de regadio no quadro da Política Agrícola Comum (PAC) e da Directiva Quadro da Água (DQA).

Nas últimas décadas, a produção agrícola do Alentejo tem estado, maioritariamente, associada aos sistemas cerealíferos e à pecuária de corte. Estes sistemas foram, em parte, favorecidos e mesmo incentivados pela PAC. No passado, as medidas da PAC de apoio à produção e de suporte aos preços dos produtos conduziram a que as escolhas produtivas dos agricultores fossem efectuadas em função das actividades agrícolas mais subsidiadas e não em função da sua competitividade (FRAGOSO e MARQUES, 2007).

A partir da reforma da PAC de 1992, tem-se assistido ao progressivo desmantelamento das medidas de suporte dos preços e das ajudas directas à produção e à sua substituição por ajudas à renda. Este processo, iniciado com a reforma da PAC de 1992, foi posteriormente reforçado e aprofundado com a Agenda 2000 e, mais recentemente, com a reforma da PAC de 2003. Esta reforma preconizou o desligamento total da produção das ajudas agrícolas, dando lugar a pagamentos directos aos produtores rurais. Desse modo, a renda garantida à unidade de produção desvinculou-se da quantidade produzida. Odesligamento visa substituir todos os pagamentos por uma única subvenção, o Regime de Pagamento Único (RPU), que é atribuído à exploração agrícola tendo em conta o valor histórico das ajudas recebidas e o cumprimento de práticas de eco-condicionalidade (OLIVEIRA e FERREIRA FILHO, 2008; DOS-SANTOS, 2008). No caso português, apenas os prémios da pecuária e as ajudas agro-ambientais mantêm alguma relação com a produção.

No seguimento da PAC de 2003, a Comissão Europeia aprovou, em 2009, o Health Check (HC), tendo como finalidade preparar o quadro financeiro posterior a 2013. Para esse efeito, procedeu a ajustamentos, o mais importante dos quais implicou a desvinculação total das ajudas da produção e o acréscimo significativo da modulação no RPU e, por conseguinte, a diminuição progressiva do seu valor por exploração até ao final de 2013 (ARFINI et al., 2008). Pretendeu-se reforçar e incentivar uma agricultura competitiva e sustentável. Por isso, a reforma da PAC de 2003 e o HC poderão representar, simultaneamente, uma ameaça e uma oportunidade para as explorações agrícolas que beneficiarem do regadio de Alqueva. 
A utilização crescente do recurso água aliada a uma maior pressão ambiental conduziu à aprovação da Directiva Quadro da Água (DQA) (2000/60/CE) pelo Parlamento Europeu. Entre outros princípios, a DQA prevê a recuperação total dos custos económicos e financeiros associados à utilização da água. Os impactos directos desta medida no regadio de Alqueva traduzir-se-ão num acréscimo do custo da água de rega e, por conseguinte, numa diminuição da competitividade do regadio.

Face ao problema do aproveitamento do regadio, o objectivo principal deste estudo consiste em avaliar a competitividade do regadio de Alqueva no Sul de Portugal, na região Alentejo, em termos da combinação óptima das opções de produção e da retribuição económica dos recursos agrícolas no contexto da PAC de 2003, do HC e da DQA.Naimpossibilidade deestudar todooregadio de Alqueva, optou-se pelo estudo do Bloco de Rega do Monte Novo (BRMN) que será o próximo a entrar em funcionamento. A metodologia utilizada baseou-se no desenvolvimento de um modelo de programação matemática multi-período, ajustado às características específicas das explorações agrícolas representativas do BRMN.

Para além desta introdução, o artigo inclui uma breve caracterização do BRMN, a metodologia, os resultados e as conclusões.

\section{O bloco de rega do Monte Novo}

O BRMN ocupa uma superfície global de 25 mil hectares, dos quais 7,1 mil ha abrangem cerca de 112 explorações agrícolas que serão beneficiadas pelo regadio de Alqueva. Como no resto do Alentejo, o clima é de cariz mediterrâneo, caracterizado por Verões secos e quentes com elevado número de horas de sol, e os solos apresentam boa aptidão para o regadio (FRAGOSO e MARQUES, 2007). A estrutura fundiária é dominada por explorações de grande dimensão e a superfície agrícola útil (SAU) é explorada principalmente com culturas de sequeiro como pastagens naturais e pousios, girassol, forragens, trigo, cevada e aveia. Nas áreas dos regadios privados já existentes, o milho assume-se como a principal cultura. Para identificar e caracterizar as explorações agrícolas representativas do BRMN aplicou-se um questionário a uma amostra de 30 explorações agrícolas seleccionadas por conveniência de um universo inicial de 112 explorações (MALHOTRA, 2001; DOS-SANTOS et al., 2011).

As variáveis obtidas pela aplicação do questionário foram sujeitas a um tratamento de dados em duas fases: fase preparatória e análise de clusters de variáveis (DOS-SANTOS, 2008). $\mathrm{Na}$ fase preparatória foi realizada uma análise de correlação para identificar as variáveis do questionário que se encontram correlacionadas. Como resultado, foi obtida uma matriz com 30 casos e 20 variáveis. Na análise de clusters estimou-se a matriz de semelhança através da distância euclidiana ao quadrado, agregaram-se os elementos com maior proximidade utilizando o critério de Ward e obtiveram-se três grupos homogéneos de empresas agrícolas (HAIR, 2005).

Os resultados dessa análise permitiram concluir que as explorações agrícolas do BRMN se diferenciam pela extensão da SAU e da superfície irrigável, nomeadamente da que já existe e da que irá beneficiar no futuro com o projecto de Alqueva, pelos recursos humanos e pelos planos de produção. Foram identificados três conjuntos de factores que serviram de base à análise de clusters das explorações, resultando os seguintes grupos homogéneos de explorações agrícolas:

- Grupo I - explorações agrícolas com uma SAU entre 50 e 450 hectares, que representam $11 \%$ da superfície irrigável a beneficiar com o projecto de Alqueva, e em que o plano de produção no regadio inclui trigo duro, girassol, milho e vinha. Nestas explorações, os dirigentes têm, em média, 59 anos de idade e possuem oito anos de escolaridade, e os rendimentos das actividades vegetais são complementados pela criação de bovinos de corte.

- Grupo II - explorações com uma SAU entre 450 e 1.400 ha, que irão beneficiar 
com quase metade da futura área do novo regadio e em que os dirigentes, em média, não têm mais de 47 anos e possuem 13 anos de escolaridade. Os planos de produção destas explorações no regadio incluem trigo duro, milho, girassol e vinha, mas também forragens, o que faz com que a pecuária de corte seja uma actividade muito importante.

- Grupo III - explorações com mais de 1.400 ha de SAU, que se prevê virem a beneficiar de 39\% da área do regadio de Alqueva, cujos dirigentes têm um perfil semelhante aos das explorações do grupo II, apenas com maior número de anos de escolaridade. Em termos do plano de produção de regadio, para além das culturas que estão presentes nos outros dois grupos de explorações, verifica-se uma forte implantação da vinha e a realização de importantes investimentos na área do olival. A pecuária de corte é de bovinos, com uma expressão muito reduzida.

Para seleccionar as explorações representativas desses três grupos homogéneos, entre os 30 casos, procedeu-se a uma análise discriminante. Esta análise utilizou o critério discriminante de Fisher para duas ou mais funções e o teste estatístico Lambda de Wilk, tendo-se rejeitado a hipótese das médias das três funções serem iguais (DOS-SANTOS, 2008). Através do cálculo da distância de
Mahalanobis ao quadrado, determinaram-se as três explorações agrícolas A, B e C representativas do BRMN, cujas principais características estruturais são apresentadas na Tabela 1.

\section{Metodologia}

São vários os métodos para estudar a competitividade consoante se trate de uma abordagem ao nível dos sectores económicos ou ao nível das empresas (FERREIRA FILHO, ALVES e DEL VILLAR, 2009). Neste estudo, o modelo multi-período revelou-se a metodologia mais adequada porque permite captar, em termos de competitividade, os efeitos associados às alterações estruturais proporcionadas pelas novas áreas de regadio, como as alterações tecnológicas, o investimento privado, os fluxos financeiros na empresa e as tendências da política agrícola e económica (HENRIQUES, 1995, DOS-SANTOS, 2008).

O modelo multi-período é baseado nos trabalhos desenvolvidos por Blanco (1996), Henriques (1995), Fragoso e Marques (2009) e Dos-Santos (2008) e capta as alterações na riqueza do produtor (investimento e retorno dos capitais da empresa) em função das condicionantes técnicas, institucionais e económicas, decorrentes da PAC de 2003 do HC, da DQA, do novo regadio público de Alqueva e da adopção de inovação tecnológica. O objectivo é determinar a

Tabela 1. Características das explorações agrícolas representativas.

\begin{tabular}{|c|c|c|c|}
\hline \multirow{2}{*}{ Características } & \multicolumn{3}{|c|}{ Explorações } \\
\hline & A & B & C \\
\hline Representatividade em termos da SAU total & $9 \%$ & $56 \%$ & $35 \%$ \\
\hline Superfície agrícola útil (ha) & 350 & 1334 & 1775 \\
\hline Superfície dos regadios privados (ha) & 116 & 250 & 477 \\
\hline Superfície dos regadios de Alqueva (ha) & 50 & 150 & 615 \\
\hline Forma de organização das explorações & Empresário individual & Empresário individual & Sociedade anónima \\
\hline Idade do dirigente da exploração (anos) & 55 & 45 & 44 \\
\hline Escolaridade do dirigente da exploração (anos) & 9 & 12 & 17 \\
\hline Actividade agrícola de regadio & Girassol, trigo e milho & $\begin{array}{l}\text { Girassol, trigo, milho } \\
\text { forragem e vinha }\end{array}$ & Girassol, trigo e milho \\
\hline Pecuária de corte (unidades pecuárias) & 120 & 250 & \\
\hline
\end{tabular}

Fonte: Resultados da análise discriminante. 
combinação óptima de actividades de produção, de investimento, de financiamento e de aquisição de serviços na empresa agrícola que maximizam a riqueza da empresa e, por essa via, o consumo do empresário.

Todas as decisões são tomadas em função dos níveis de consumo do produtor e das expectativas de ocorrência de diferentes condições de mercado, de produção agrícola e de água disponível para pôr em prática o plano de produção. Deste modo, o modelo simula as estratégias dos produtores agrícolas em cenários com alterações técnicas, institucionais e económicas, prevendo a passagem do sequeiro para regadio, a substituição entre culturas de regadio, a substituição de culturas de regadio por culturas de sequeiro e o reforço ou o abandono da actividade agrícola.

A estrutura simplificada do modelo pode ser demonstrada através das seguintes relações matemáticas:

$$
\operatorname{Max} Z=\sum_{n=1}^{N} \frac{C_{n}(1-0,4)+A-\phi \sigma_{n}}{(1+i)^{n-1}}
$$

s.a:

$$
\begin{aligned}
& \sigma_{n}=\sum_{t=1}^{T} \sum_{f=1}^{F} p_{t}^{f} \sqrt{\sum_{t=1}^{T} \sum_{f=1}^{F}\left(C_{n}-C_{n}^{f, t}\right)^{2}} \\
& \sum_{j=1}^{J} n w_{j} X_{n}^{j} \leq Q+w \\
& Q \leq E(q)-k_{\alpha} \sigma_{q} \\
& \sum_{j=1}^{J} n i_{j} X_{n}^{j} \leq i a+\sum_{j=1}^{n-k} I_{n-k}+I_{n} \\
& B_{n-1}+S L_{n} \geq \sum_{j}^{J} e_{j} X_{n}^{j}+(1+t x) S L_{n-1}+O E_{n} \\
& \sum_{n=1}^{n-k} C_{n}(1-0,6)-\sum_{n=1}^{n-k} S C_{n-1}+L{ }_{n}+S I_{n} \geq I C_{n}
\end{aligned}
$$

A função objectivo na equação (1) maximiza o valor actualizado dos activos líquidos e minimiza o valor actualizado do desvio padrão dos cashflow anuais. $\mathrm{O}$ valor actual dos activos líquidos resulta da soma dos valores actualizados, dos consumos acumulados do produtor com o valor final dos activos fixos $(A)$. O consumo do produtor depende das variáveis que determinam o cash-flow anual da empresa $\left(C_{n}\right)$ e da propensão marginal ao consumo. O risco é calculado em função do coeficiente de aversão ao risco $\phi$ e do desvio padrão dos cash-flow anuais $\left(\sigma_{n}\right)$, tendo em consideração a probabilidade de ocorrência $\left(p_{t}^{f}\right)$ de cinco estados de natureza de produção $(t)$ e três de mercado $(f)$.

O cash-flow anual da empresa é dado pela soma dos cash-flow parciais das actividades agrícolas e pelas receitas e despesas comuns. As actividades agrícolas incluem culturas em regime de sequeiro e em regime de regadio e bovinos de carne. As primeiras podem ser levadas a cabo de acordo com a tecnologia tradicional ou com base em tecnologias inovadoras como a da sementeira directa. As actividades vegetais são contabilizadas em hectares e as actividades de bovinos, em unidades pecuárias.

O valor da função objectivo depende das restrições de disponibilidade deágua, dos recursos terra, trabalho e capital, da complementaridade entre as actividades vegetais e animais e das restrições de liquidez e de solvabilidade.

As equações (3) e (4) traduzem as condições de disponibilidade e uso da água. A primeira garante que as reservas de água privadas $(q)$ e públicas de Alqueva (w) não são excedidas pela procura. Neste caso, a procura de água depende das necessidades de rega por hectare da cultura $j\left(n w_{j}\right)$ e da respectiva área em hectares $\left(X_{n}^{j}\right)$. A segunda equação introduz o risco de disponibilidade de água nos regadios privados através de uma restrição probabilística, formulada de acordo com Varela-Ortega et al. (1998) e com Fragoso e Marques (2009). Este método pressupõe que o agricultor irá eleger um plano de produção que poderá realizar na maioria das vezes, limitando-se superiormente a variável $Q_{n}$ ao valor do parâmetro estocástico com distribuição normal $\left(E(q)-K_{\alpha} \times \sigma_{q}\right) . E(q)$ é o valor médio anual da disponibilidade água privada, $K_{\alpha}$ é o percentil estandardizado da distribuição normal até à probabilidade $\alpha$ de não haver água e $\sigma_{q}$ é o desvio padrão da distribuição 
da disponibilidade anual de água. De acordo com a frequência relativa da dotação observada nos perímetros de rega locais, considerou-se que $K_{\alpha}$ é de 0,60 .

A utilização de bens de capital e a realização de novos investimentos estão representadas na equação (5). No primeiro membro calculam-se as necessidades de utilização, escalando as variáveis das actividades agrícolas produtivas $\left(X_{n}^{j}\right)$ pelos respectivos coeficientes técnicos $\left(n i_{j}\right)$. O nível de utilização desses bens de capital não pode exceder a capacidade já instalada (ia) mais a capacidade contratualizada através dos novos investimentos $\left(I_{n}\right)$ em cada ano $n$ do horizonte temporal. As actividades de investimento prevêem a aquisição de máquinas e equipamentos agrícolas, equipamento de rega, animais reprodutores e a instalação de novas plantações.

As equações (6) e (7) dizem respeito ao financiamento da empresa no curto e no longo prazo, respectivamente. No primeiro caso, as disponibilidades financeiras dadas pelo saldo de tesouraria do ano anterior $\left(B_{n-1}\right)$ e pelos empréstimos de curto prazo $\left(S L_{n}\right)$, devem ser suficientes para fazer face às obrigações com as despesas $\left(e_{j}\right)$ das actividades agrícolas $\left(X_{n}{ }^{j}\right)$, com a liquidação dos empréstimos contratados no ano anterior $\left(S L_{n-1}\right)$ à taxa de juro anual $(t x)$ e com outras despesas $(O E)$, como a remuneração do trabalho directivo do empresário agrícola e as anuidades dos empréstimos de longo prazo. No segundo caso, garante-se que os custos do investimento $\left(I C_{n}\right)$ realizados no ano $n$ são financiados pelos capitais próprios do empresário $\left(S C_{n}\right)$, pelos empréstimos de longo prazo $\left(L L_{n}\right)$ contratados no ano $n$ e pelos subsídios governamentais atribuídos a fundo perdido. Os capitais próprios do empresário resultam das poupanças acumuladas, que captam todos os anos a parte do cash-flow da empresa que não é canalizada para o consumo.

Para representar adequadamente o contexto técnico, institucional e económico em que operam os empresários agrícolas do BRMN, o modelo também inclui restrições que modelam a utilização de mão de obra operativa, restrições agronómicas e de mercado e a complementaridade entre actividades vegetais e pecuárias com base no balanço forrageiro da empresa agrícola.

\section{Resultados e discussão}

A propensão marginal para o consumo foi fixada nas três explorações agrícolas representativas em $60 \%$ do valor do cash-flow. Este valor é o único disponível para a agricultura em Portugal e foi estimado por Henriques (1995) como o valor médio das empresas agrícolas no Alentejo. Os restantes $40 \%$ do valor do cash-flow são a poupança do empresário que financia os capitais próprios da empresa.

Para garantir que o modelo traduz o comportamento do empresário agrícola, nomeadamente a sua atitude face ao risco, procedeu-se à sua validação parametrizando o coeficiente de aversão ao risco $(\phi)$ de acordo com três níveis de risco $(0,20,0,50$ e 1$)$. O valor seleccionado para o coeficiente $\phi$ foi 0,20 , por ser o que melhor reproduz, na situação de referência (ano agrícola de 2004/2005), o plano de produção e os resultados económicos dos empresários agrícolas. De modo geral, os resultados mostraram que existe um bom ajustamento dos modelos aos dados, uma vez que o valor do desvio absoluto ponderado é de 1,4, 0,8, e 9,4\%, respectivamente, para as explorações A, B e C do BRMN. De acordo com Hazell e Norton (1986), e face aos resultados obtidos, estes modelos podem considerar-se calibrados e válidos como instrumentos de análise económica.

Para avaliar a competitividade do regadio de Alqueva no contexto das explorações agrícolas representativas do BRMN, foram considerados os seguintes cenários de política económica:

- Cenário I - representa a situação de referência em que vigoram as ajudas agrícolas parcialmente associadas à produção preconizadas no quadro institucional da Agenda 2000;

- Cenário II - considera o desligamento total das ajudas agrícolas à produção 
introduzido com a reforma da PAC de 2003 e reforçado com o Health Check em 2009;

- Cenário III - considera o desligamento total das ajudas agrícolas à produção introduzido com a reforma da PAC de 2003 e reforçado com o Health Check em 2009 e a entrada em funcionamento do regadio de Alqueva no BRMN;

- Cenário IV - para além do desligamento das ajudas agrícolas e da entrada em funcionamento do BRMN, neste cenário também se considera a possibilidade das explorações introduzirem, nos seus planos de produção, actividades de maior valor acrescentado, como horto-industriais, hortofrutícolas, frutas e culturas mediterrâneas e tecnologias de produção com menores custos e melhores condições ambientais, como é o caso da sementeira directa.

Nas Tabelas 2, 3 e 4 apresentam-se o valor actual dos activos líquidos (VAAL), o valor do investimento e a evolução do comportamento dos empresários agrícolas em termos da ocupação da superfície agrícola utilizada (SAU) e da contratação de mão de obra, ao longo dos dez anos do horizonte temporal, nos quatro cenários considerados, para cada uma das explorações agrícolas $\mathrm{A}, \mathrm{B}$ e $\mathrm{C}$, respectivamente.
Inicialmente, a área potencial de regadio, definida como superfície irrigável, é de 116 ha na empresa A, 250 ha na empresa B e de 477 ha na empresa C. Em termos de superfície agrícola utilizada, essas áreas de superfície irrigável representam, respectivamente, 33, 19 e 27\% da SAU. Os resultados do Cenário I apontam para níveis de utilização desse potencial de regadio em cada uma das três explorações de $20 \%$ a 25\%,17\% e $25 \%$, que estão associados a um VAAL de 456 , 1.284 e 641 mil euros, a um nível de investimento agrícola de 175, 818 e 1.817 mil euros e a uma força de trabalho de cerca de 1,3, 9 e 10 Unidades de Trabalho Anual (UTA).

O desligamento total das ajudas agrícolas da produção (decoupling), introduzido no cenário II, traduziu-se numa perda de importância do regadio nas três explorações e na reorientação para a produção de forragens e pastagens nas explorações A e B. As reduções na superfície irrigada variaram desde dois terços da SAU na empresa A até ao seu abandono total na empresa C. Em virtude destas alterações, o volume de trabalho diminuiu acentuadamente, entre $40 \%$ a $60 \%$ em todas as explorações, o VAAL diminuiu entre $18,5 \%$ e $65 \%$ nas explorações A e B e o investimento diminuiu $92 \%$ na exploração B e aproximadamente $50 \%$ nas restantes. 
Tabela 2. Resultados da Exploração Agrícola A nos cenários I, II, III e IV.

\begin{tabular}{|c|c|c|c|c|c|c|c|c|c|c|}
\hline Anos & 2005 & 2006 & 2007 & 2008 & 2009 & 2010 & 2011 & 2012 & 2013 & 2014 \\
\hline \multicolumn{11}{|l|}{ Cenário I } \\
\hline Valor actual dos activos líquidos (Euros) & & & & & & & & & \multicolumn{2}{|c|}{456.097} \\
\hline Investimentos (Euros) & & & & & & & & & \multicolumn{2}{|c|}{174.545} \\
\hline Trabalho (unidades trabalho anual) & 1,3 & 1,3 & 1,3 & 1,3 & 1,3 & 1,2 & 1,0 & 1,0 & 1,0 & 1,0 \\
\hline Superfície Irrigada em \% da SAU: & 33,2 & 33,2 & 32,8 & 33,2 & 33,2 & 33,2 & 24,1 & 24,1 & 24,1 & 24,1 \\
\hline Cereais e oleaginosas & 33,2 & 33,2 & 32,8 & 33,2 & 33,2 & 33,2 & 24,1 & 24,1 & 24,1 & 24,1 \\
\hline Superfície de sequeiro & 66,8 & 66,8 & 67,2 & 66,8 & 66,8 & 66,8 & 75,9 & 75,9 & 75,9 & 75,9 \\
\hline \multicolumn{11}{|l|}{ Cenário II } \\
\hline Valor actual dos activos líquidos (Euros) & & & & & & & & & \multicolumn{2}{|c|}{371.685} \\
\hline Investimentos (Euros) & & & & & & & & & \multicolumn{2}{|c|}{118.177} \\
\hline Trabalho (unidades trabalho anual) & 0,8 & 0,8 & 0,8 & 0,8 & 0,8 & 0,7 & 0,7 & 0,7 & 0,7 & 0,7 \\
\hline Superfície Irrigada em $\%$ da SAU: & 10,0 & 10,0 & 10,0 & 10,0 & 15,0 & 15,0 & 9,9 & 9,9 & 9,9 & 4,6 \\
\hline Cereais e oleaginosas & & & & & 5,9 & 5,9 & & & & \\
\hline Pastagens e forragens & 10,0 & 10,0 & 10,0 & 10,0 & 9,2 & 9,1 & 9,9 & 9,9 & 9,9 & 4,6 \\
\hline Superfície de sequeiro em $\%$ da SAU & 90,0 & 90,0 & 90,0 & 90,0 & 85,0 & 85,0 & 90,1 & 90,1 & 90,1 & 95,4 \\
\hline \multicolumn{11}{|l|}{ Cenário III } \\
\hline Valor actual dos activos líquidos (Euros) & & & & & & & & & \multicolumn{2}{|c|}{407.543} \\
\hline Investimentos (Euros) & & & & & & & & & \multicolumn{2}{|c|}{267,893} \\
\hline Trabalho (unidades trabalho anual) & 2,1 & 2,1 & 2,1 & 2,1 & 0,9 & 0,9 & 0,7 & 0,7 & 0,7 & 0,7 \\
\hline Superfície Irrigada em \% da SAU: & 24,3 & 24,3 & 24,3 & 24,3 & 25,9 & 26 & 8,6 & 8,6 & 8,6 & 8,6 \\
\hline Cereais e oleaginosas & & & & & 15,8 & 15,8 & & & & \\
\hline Pastagens e forragens & 24,3 & 24,3 & 24,3 & 24,3 & 10,1 & 10,2 & 8,6 & 8,6 & 8,6 & 8,6 \\
\hline Superfície de sequeiro em $\%$ da SAU & 75,7 & 75,7 & 75,7 & 75,7 & 74,1 & 74 & 82,6 & 82,6 & 82,6 & 91,4 \\
\hline Abandono em $\%$ da SAU & & & & & & & 8,8 & 8,8 & 8,8 & 1,5 \\
\hline \multicolumn{11}{|l|}{ Cenário IV } \\
\hline Valor actual dos activos líquidos (Euros) & & & & & & & & & \multicolumn{2}{|c|}{457.082} \\
\hline Investimentos (Euros) & & & & & & & & & \multicolumn{2}{|c|}{404.439} \\
\hline Trabalho (unidades trabalho anual) & 2,7 & 2,7 & 2,3 & 2,8 & 3,5 & 3,4 & 3,1 & 3,1 & 3,1 & 3,0 \\
\hline Superfície Irrigada em \% da SAU: & 24,6 & 25 & 19,2 & 22,4 & 32,7 & 29 & 19,7 & 19,7 & 19,7 & 21,1 \\
\hline Cereais e oleaginosas & 2,8 & 2,4 & 2,7 & 2,8 & 10,2 & 8,8 & 1,4 & 1,4 & 1,4 & 1,4 \\
\hline Pastagens e forragens & 5,6 & 5,6 & 5,6 & 5,6 & 5,6 & 4,3 & 2,8 & 2,8 & 2,8 & 2,8 \\
\hline Horto-frutícolas e industriais & 8,0 & 8,0 & 1,6 & 4,7 & 7,6 & 6,6 & 6,2 & 6,2 & 6,2 & 7,6 \\
\hline Culturas mediterrânicas & 8,2 & 9,0 & 9,3 & 9,3 & 9,3 & 9,3 & 9,3 & 9,3 & 9,3 & 9,3 \\
\hline Superfície de sequeiro em $\%$ da SAU & 75,4 & 75,0 & 80,8 & 77,6 & 67,3 & 71,0 & 73,5 & 73,5 & 73,5 & 72,1 \\
\hline Abandono em $\%$ da SAU & & & & & & & 6,8 & 6,8 & 6,8 & 6,8 \\
\hline
\end{tabular}

Fonte: Resultados do modelo. 
Tabela 3. Resultados da Exploração Agrícola B nos cenários I, II, III e IV.

\begin{tabular}{|c|c|c|c|c|c|c|c|c|c|c|}
\hline Anos & 2005 & 2006 & 2007 & 2008 & 2009 & 2010 & 2011 & 2012 & 2013 & 2014 \\
\hline Cenário I & & & & & & & & & \multicolumn{2}{|c|}{1.283 .784} \\
\hline Investimentos (Euros) & & & & & & & & & \multicolumn{2}{|c|}{818.115} \\
\hline Trabalho (unidades trabalho anual) & 9,1 & 9,0 & 9,0 & 9,0 & 9,0 & 9,0 & 9,0 & 9,0 & 9,0 & 9,0 \\
\hline Superfície Irrigada em $\%$ da SAU: & 18,7 & 18,7 & 18,7 & 18,7 & 18,7 & 18,7 & 18,7 & 18,7 & 18,7 & 18,7 \\
\hline Cereais e oleaginosas & 14,6 & 14,6 & 14,6 & 14,6 & 14,6 & 14,6 & 14,6 & 14,6 & 14,6 & 14,6 \\
\hline Pastagens e forragens & 1,1 & 1,1 & 1,1 & 1,1 & 1,1 & 1,1 & 1,1 & 1,1 & 1,1 & 1,1 \\
\hline Culturas mediterrânicas & 3,0 & 3,0 & 3,0 & 3,0 & 3,0 & 3,0 & 3,0 & 3,0 & 3,0 & 3,0 \\
\hline Superfície de sequeiro em $\%$ da SAU & 81,3 & 81,3 & 81,3 & 81,3 & 81,3 & 81,3 & 81,3 & 81,3 & 81,3 & 81,3 \\
\hline \multicolumn{11}{|l|}{ Cenário II } \\
\hline Valor actual dos activos líquidos (Euros) & & & & & & & & & \multicolumn{2}{|c|}{449.821} \\
\hline Investimentos (Euros) & & & & & & & & & \multicolumn{2}{|c|}{64.072} \\
\hline Trabalho (unidades trabalho anual) & 6,6 & 6,6 & 5,6 & 5,6 & 4,2 & 4,2 & 4,1 & 3,9 & 3,7 & 3,7 \\
\hline Superfície Irrigada em \% da SAU: & 18,8 & 18,8 & 9,0 & 9,0 & 8,6 & 8,6 & 8,3 & 3,0 & 3,0 & 3,0 \\
\hline Cereais e oleaginosas & 14,6 & 14,6 & 3,8 & 3,8 & 3,3 & 3,3 & 3,0 & & & \\
\hline Pastagens e forragens & 1,2 & 1,2 & 2,2 & 2,2 & 2,3 & 2,3 & 2,3 & & & \\
\hline Culturas mediterrânicas & 3,0 & 3,0 & 3,0 & 3,0 & 3,0 & 3,0 & 3,0 & 3,0 & 3,0 & 3,0 \\
\hline Superfície de sequeiro em $\%$ da SAU & 45,1 & 45,1 & 39,6 & 39,6 & 5,5 & 5,5 & 5,7 & 6,9 & 5,3 & 5,3 \\
\hline Abandono em $\%$ da SAU & 36,1 & 36,1 & 51,4 & 51,4 & 85,9 & 85,9 & 86,0 & 90,1 & 91,7 & 91,7 \\
\hline \multicolumn{11}{|l|}{ Cenário III } \\
\hline Valor actual dos activos líquidos (Euros) & & & & & & & & & \multicolumn{2}{|c|}{1.269 .311} \\
\hline Investimentos (Euros) & & & & & & & & & \multicolumn{2}{|c|}{576.434} \\
\hline Trabalho (unidades trabalho anual) & 9,7 & 9,7 & 9,2 & 9,2 & 7,1 & 7,1 & 7,1 & 7,1 & 7,1 & 7,1 \\
\hline Superfície Irrigada em $\%$ da SAU: & 18,8 & 18,8 & 9,0 & 9,0 & 9,0 & 9,0 & 9,0 & 3,5 & 3,5 & 3,5 \\
\hline Cereais e oleaginosas & 7,3 & 7,5 & & & 5,5 & 5,5 & 5,5 & & & \\
\hline Pastagens e forragens & 8,5 & 8,3 & 6,0 & 6,0 & 0,5 & 0,5 & 0,5 & 0,5 & 0,5 & 0,5 \\
\hline Culturas mediterrânicas & 3,0 & 3,0 & 3,0 & 3,0 & 3,0 & 3,0 & 3,0 & 3,0 & 3,0 & 3,0 \\
\hline Superfície de sequeiro em $\%$ da SAU & 81,2 & 81,2 & 91,0 & 91,0 & 91,0 & 91,0 & 91 & 96,5 & 96,5 & 96,5 \\
\hline \multicolumn{11}{|l|}{ Cenário IV } \\
\hline Valor actual dos activos líquidos (Euros) & & & & & & & & & \multicolumn{2}{|c|}{1.701 .404} \\
\hline Investimentos (Euros) & & & & & & & & & \multicolumn{2}{|c|}{1.334 .031} \\
\hline Trabalho (unidades trabalho anual) & 13,5 & 13,3 & 13,9 & 13,9 & 12,9 & 12,9 & 12,9 & 12,9 & 12,9 & 12,9 \\
\hline Superfície Irrigada em $\%$ da SAU: & 18,7 & 18,8 & 18,8 & 18,8 & 16,6 & 16,6 & 16,5 & 15,4 & 15,4 & 15,4 \\
\hline Pastagens e forragens & 3,4 & 2,6 & 2,8 & 2,8 & 0,4 & 0,4 & 0,3 & 0,1 & 0,1 & 0,1 \\
\hline Horto-frutícolas e industriais & 7,3 & 7,2 & 7,0 & 7,0 & 7,2 & 7,2 & 7,2 & 6,3 & 6,3 & 6,3 \\
\hline Culturas mediterrânicas & 8,0 & 9,0 & 9,0 & 9,0 & 9,0 & 9,0 & 9,0 & 9,0 & 9,0 & 9,0 \\
\hline Superfície de sequeiro em $\%$ da SAU & 44,8 & 49,1 & 39,1 & 39,1 & 5,8 & 5,4 & 5,3 & 6,5 & 6,5 & 6,5 \\
\hline Abandono em $\%$ da SAU & 36,5 & 32,1 & 42,1 & 42,1 & 77,6 & 78,0 & 78,2 & 78,1 & 78,1 & 78,1 \\
\hline
\end{tabular}

Fonte: Resultados do modelo. 
Tabela 4. Resultados da Exploração Agrícola C nos cenários I, II, III e IV.

\begin{tabular}{|c|c|c|c|c|c|c|c|c|c|c|}
\hline Anos & 2005 & 2006 & 2007 & 2008 & 2009 & 2010 & 2011 & 2012 & 2013 & 2014 \\
\hline \multicolumn{11}{|l|}{ Cenário I } \\
\hline Valor actual dos activos líquidos (Euros) & & & & & & & & \multicolumn{3}{|c|}{641.358} \\
\hline Investimentos (Euros) & & & & & & & \multicolumn{4}{|c|}{1.816 .500} \\
\hline Trabalho (unidades trabalho anual) & 10,5 & 9,1 & 8,9 & 9,4 & 10,5 & 10,5 & 10,5 & 10,5 & 10,5 & 10,5 \\
\hline \multicolumn{11}{|l|}{ Actividades agrícolas em $\%$ da SAU: } \\
\hline Superfície Irrigada & 26,6 & 26,6 & 14,9 & 16,6 & 26,6 & 26,6 & 26,6 & 26,6 & 26,6 & 26,6 \\
\hline Cereais e oleaginosas & 26,6 & 26,6 & 14,9 & 16,6 & 26,6 & 26,6 & 26,6 & 26,6 & 26,6 & 26,6 \\
\hline Superfície de sequeiro em $\%$ da SAU & 73,4 & 73,4 & 85,1 & 83,4 & 73,4 & 73,4 & 73,4 & 73,4 & 73,4 & 73,4 \\
\hline \multicolumn{11}{|l|}{ Cenário II } \\
\hline Valor actual dos activos líquidos (Euros) & & & & & & & & \multicolumn{3}{|c|}{1.197 .897} \\
\hline Investimentos (Euros) & & & & & & & & \multicolumn{3}{|c|}{997.236} \\
\hline Trabalho (unidades trabalho anual) & 6,7 & 6,7 & 6,7 & 6,7 & 6,7 & 6,7 & 6,7 & 6,7 & 6,7 & 6,7 \\
\hline Superfície Irrigada \% da SAU: & 0,0 & 0,0 & 0,0 & 0,0 & 0,0 & 0,0 & 0,0 & 0,0 & 0,0 & 0,0 \\
\hline Superfície de sequeiro em $\%$ da SAU & 100,0 & 100,0 & 100,0 & 100,0 & 100,0 & 100,0 & 100,0 & 100,0 & 10,00 & 100,0 \\
\hline \multicolumn{11}{|l|}{ Cenário III } \\
\hline Valor actual dos activos líquidos (Euros) & & & & & & & & \multicolumn{3}{|c|}{1.213 .897} \\
\hline Investimentos (Euros) & & & & & & & & \multicolumn{3}{|c|}{997.978} \\
\hline Trabalho (unidades trabalho anual) & 6,7 & 6,7 & 6,7 & 6,7 & 6,7 & 6,7 & 6,7 & 6,7 & 6,7 & 6,7 \\
\hline Superfície Irrigada $\%$ da SAU: & 0,0 & 0,0 & 0,0 & 0,0 & 0,0 & 0,0 & 0,0 & 0,0 & 0,0 & 0,0 \\
\hline Superfície de sequeiro & 100,0 & 100,0 & 100,0 & 100,0 & 100,0 & 100,0 & 100,0 & 100,0 & 10,00 & 100,0 \\
\hline \multicolumn{11}{|l|}{ Cenário IV } \\
\hline Valor actual dos activos líquidos (Euros) & & & & & & & & & \multicolumn{2}{|c|}{7.474 .177} \\
\hline Investimentos (Euros) & & & & & & & & & \multicolumn{2}{|c|}{3.405 .211} \\
\hline Trabalho (unidades trabalho anual) & 20,2 & 22,5 & 17,0 & 16,9 & 12,6 & 11,8 & 10,4 & 10,4 & 11,0 & 11,0 \\
\hline Superfície Irrigada em $\%$ da SAU: & 35,1 & 37,1 & 28,8 & 29,8 & 25,1 & 24,8 & 24,5 & 24,5 & 24,7 & 24,7 \\
\hline Pastagens e forragens & 5,7 & 6 & 5,2 & 5,2 & 0,4 & 0,2 & & & & \\
\hline Horto-frutícolas e industriais & 18,3 & 18 & 10,5 & 11,5 & 11,6 & 11,5 & 11,4 & 11,4 & 11,6 & 11,6 \\
\hline Culturas mediterrânicas & 11,1 & 13,1 & 13,1 & 13,1 & 13,1 & 13,1 & 13,1 & 13,1 & 13,1 & 13,1 \\
\hline Superfície de sequeiro em $\%$ da SAU & 64,9 & 62,9 & 71,2 & 70,2 & 74,9 & 75,2 & 75,5 & 75,5 & 75,3 & 75,3 \\
\hline
\end{tabular}

Fonte: Resultados do modelo.

No cenário III, a entrada em funcionamento do BRMN permite aumentar a superfície irrigável das explorações A, B e C de 116, 250 e 477 ha para 166, 400 e 1.092 ha, respectivamente, e melhorar as garantias de água, especialmente nos anos mais secos. No entanto, estas melhorias estruturais, por si só, não alteram grandemente a situação prevista no cenário anterior, porque, apesar de as explorações disporem das infraestruturas de rega, não aproveitam esse potencial. A subida progressiva do custo da água ao longo dos anos do horizonte temporal origina o decréscimo da superfície irrigada nas explorações A e B em mais de $50 \%$. Essa subida do custo da água decorre das orientações da DQA e faz-se sentir nas explorações A e B, sobretudo a partir dos anos 2011 e 2012. Esta situação coincide com a redução de receitas originado pelo desligamento completo das ajudas da PAC às actividades pecuárias e pela modulação do seu valor em prol do fundo europeu do desenvolvimento rural.

Como consequência, o VAAL diminui entre $10 \%$ e $1 \%$ das explorações A e B, apesar de o investimento aumentar $54 \%$ na primeira e diminuir $29 \%$ na segunda. A empresa C, que se dedica exclusivamente à produção de cereais e oleaginosas, não regista alterações no comportamento do produtor, mas, devido ao 
efeito do desligamento das ajudas da componente produtiva, o VAAL apresenta uma subida significativa e praticamente duplica nos cenários II e III, apesar de o investimento se reduzir para metade do seu valor original no cenário I.

O cenário IV, em que, para além da entrada em funcionamento do regadio de Alqueva no BRMN também se prevê a realização de investimentos em novas tecnologias, traduz-se em impactos extremamente positivos no aproveitamento do regadio, na utilização dos recursos e nos resultados económicos das três explorações agrícolas. Apesar do custo unitário da água do regadio de Alqueva ser crescente ao longo do horizonte temporal, o aproveitamento da superfície irrigada aumenta consideravelmente em relação ao cenário III e mantém-se estável a prazo em todas as explorações agrícolas. Para as três explorações agrícolas, as opções tradicionais de culturas arvenses e forrageiras no regadio dão lugar às culturas mediterrânicas $(9 \%$ a $13 \%$ da $\mathrm{SAU})$ e às culturas horto-frutícolas e industriais (6\% a $12 \%$ da SAU). As primeiras incluem a vinha e o olival, e as últimas compreendem as áreas de beterraba, tomate para indústria, batata e cebola. Para além da alteração das opções produtivas a considerar no plano de produção, as tecnologias tradicionais de mobilização do solo são substituídas, na maior parte dos casos, pela sementeira directa. A pecuária de corte continua a manter uma importância relativa na economia das empresas agrícolas do BRMN, passando inclusivamente a ser também praticada na exploração C. Em virtude dessas alterações, o volume de trabalho mais do que duplica, chegando a triplicar no caso da empresa C.

Como seria de esperar, os resultados económicos das empresas agrícolas do BRMN sofrem melhorias significativas relativamente aos cenários anteriores. Comparativamente ao cenário I, o VAAL cresce cerca de um terço na exploração B e mais de 11 vezes na exploração $C$ e o investimento mais do que duplica. Comparando com o cenário II, os aumentos do VAAL são de $23 \%$ nas explorações agrícolas do tipo A, quase quatro vezes na exploração $B$ e mais de seis vezes na exploração C. Quando se comparam os resultados obtidos com os do cenário III, verifica-se que a adopção de acções inovadoras proporcionam aumentos do VAAL da ordem dos $12 \%$ e $34 \%$ nas explorações A e B e mais de seis vezes no caso da exploração $C$.

\section{Conclusões}

Os resultados obtidos permitem concluir que o desligamento total das ajudas agrícolas (decoupling), introduzido pela PAC de 2003 e pelo HC, conduzem, de forma geral, à diminuição dos resultados económicos das empresas agrícolas e das suas relações de troca com o exterior, à extensificação da produção e à perda de importância do regadio na formação do rendimento dos agricultores. Esta conclusão corrobora a tese de vários autores, que, de modo geral, afirmam que a adopção dos regulamentos da PAC de 2003, e mais recentemente do Health Check da PAC, comporta elevados riscos de abandono da actividade agrícola.

A entrada em funcionamento do regadio de Alqueva na zona BRMN no contexto da PAC de 2003, do HC e da Directiva Quadro da Água da União Europeia, não conduz per si à valorização e ao aproveitamento do regadio. Apesar de se dispor das infraestruturas de regadio, o modelo produtivo tradicional praticado pelos agricultores não permite tirar partido do potencial económico que Alqueva pode conferir em termos da competitividade agrícola.

A possibilidade de se poderem adoptar novas tecnologias de produção de maior valor acrescentado e/ou baseadas em métodos sustentáveis nas explorações agrícolas, parece ser uma solução capaz de potenciar o desenvolvimento do regadio de Alqueva e conduzir a uma melhoria significativa dos indicadores económicos. Por outro lado, essas melhorias de desempenho terão efeitos multiplicadores na economia local, com repercussões sociais significativas, como é o caso do emprego a montante e a jusante do sector agrícola (FRAGOSO e MARQUES, 2007). 
Apesar do desligamento e da modulação das ajudas agrícolas preconizadas na PAC de 2003 e no $\mathrm{HC}$ e da entrada em vigor das disposições da Directiva Quadro da Água da União Europeia comportarem elevados riscos de abandono da actividade agrícola no Alentejo e no Sul de Portugal e da Europa, são também um estímulo à adopção de actividades sustentáveis que valorizem melhor as vantagens competitivas desses territórios, como é o caso da vinha, do olival, das horto-frutícolas e das tecnologias de sementeira directa e de mobilização reduzida.

\section{Referências bibliográficas}

\begin{abstract}
ARFINI,F,,DONATI,M.,PETRICCIONE,G.eSOLAZZO, R. An Impact Assessment of the Future CAP Reform on the Italian Sector. 109 $9^{\text {th }}$ EAAE Seminar. Disponivel em: ageconsearch.umn.edu/bitstream/44831/2/4.1.3_Donati. pdf. Acesso em: 16 ago. 2009.

BLANCO, M.F. Analyse des impacts socio-économiques et les effets sur l'environnement des politiques agricoles: Modélisation de l'utilisation agricole des ressources en eau dans la région Espagnole de Castille-Léon. (Mestrado em Economia Agrícola) - Institute Agronomique Méditerranéen de Montpellier CIHEAM. Montpellier. Montpellier, 1996. 170 p.
\end{abstract}

DIRECTIVA 200/60/EC do Parlamento Europeu e do Conselho de 23 de Outubro 2000. Directiva Quadro Água. Jornal Oficial da Comunidade Europeia 22 dez. 2000, L327, 2000, p. 1-72.

DOS-SANTOS, M.J.P.L. Análise da competitividade do regadio de Alqueva: O caso do Perímetro de Rega do Monte Novo. Tese de Doutoramento, Universidade de Évora, Évora. 2008. 276 p.

DOS SANTOS, M.J.P.L., HENRIQUES, P.D.S., FRAGOSO, R.M.S. e CARVALHO, M.L.S. As atitudes dos agricultores face à Política Agrícola Comum (PAC) e ao projecto de regadio de Alqueva, Revista de Economia e Sociologia Rural. v. 49, n. 1, 2011, p. 233-256.

FERREIRA-FILHO, J.B.S., ALVES, L.R.A. e DELVILLAR, P.M. Estudo da competitividade da produção de algodão entre Brasil e Estados Unidos - safra 2003/2004. Revista de Economia e Sociologia Rural, v. 47, n. 1, 2009, p. 59-88.

FRAGOSO, R. M. S. F. e MARQUES, C. Avaliação Económica de tarifas de água no uso agrícola: um estudo de caso no Sul de Portugal. Revista de Economia e Sociologia Rural, v. 47, n. 3, 2009. p. 699-718.

FRAGOSO, R. M. S. F. e MARQUES, C. A competitividade do regadio em Portugal no contexto da nova Política Agrícola Comum: O caso de uma exploração agrícola no Alentejo. Revista de Economia e Sociologia Rural. v. 45, n. 1, 2007, p. 49-70.

HAIR, J. R., BLACK, B., BABIN B. e ANDERSON, R. E. Multivariate data analysis. $6^{\text {th }}$ Edition, Maxwell MacMillan Editions, 2005. 799 p.

HAZELL, P.B.R. e NORTON, R.D. Mathematical programming economics analyses in agriculture. McMillan Publishing Company, New York, U.S.A, 1898. 535 p.

HENRIQUES, P.D.S. Technical efficiency and changes in Alentejan farming systems. PhD Thesis, University of Reading, Reading, UK. 1995. 266 p.

MALHOTRA, N. K. Pesquisa de marketing: uma orientação aplicada. 3. ed. Porto Alegre: Bookman, 2001. 720 p.

OLIVEIRA, S.J.M. e FERREIRA FILHO, J.B.S. A Expansão da União Européia em 2004 e seus impactos sobre o agronegócio Brasileiro. Revista de Economia e Sociologia Rural, v. 46, n. 4, 2008, p. 937-967.

VARELA-ORTEGA, C., SUMPSI, M.J., GARRIDO, A., BLANCO, M. e IGLESIAS E. Water pricing policies, public decision making and farmer's response: Implications for water policy. Agricultural Economics, v. 19, n. 1-2, 1998, p. 193-202. 